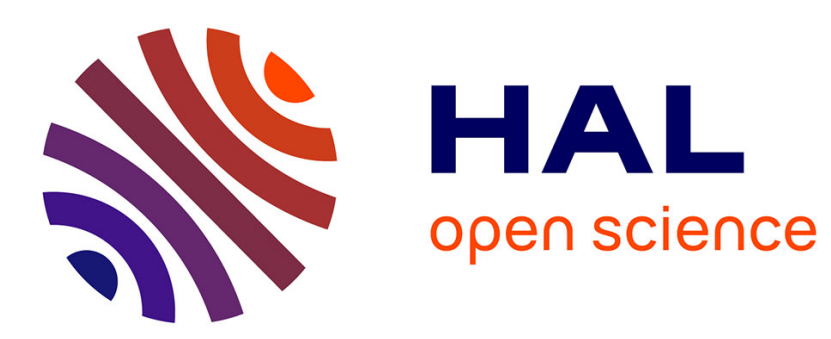

\title{
Analytic Engagement and the Perils of Reframing the Dual- and Single-Process Models Debate
}

Wim de Neys

\section{To cite this version:}

Wim de Neys. Analytic Engagement and the Perils of Reframing the Dual- and SingleProcess Models Debate. Perspectives on Psychological Science, 2021, 16 (6), pp.1432-1434. $10.1177 / 17456916211039848$. hal-03478258

\section{HAL Id: hal-03478258 \\ https://hal.science/hal-03478258}

Submitted on 13 Dec 2021

HAL is a multi-disciplinary open access archive for the deposit and dissemination of scientific research documents, whether they are published or not. The documents may come from teaching and research institutions in France or abroad, or from public or private research centers.
L'archive ouverte pluridisciplinaire HAL, est destinée au dépôt et à la diffusion de documents scientifiques de niveau recherche, publiés ou non, émanant des établissements d'enseignement et de recherche français ou étrangers, des laboratoires publics ou privés. 


\title{
Analytic Engagement And The Perils Of Reframing The Dual- And Single-Process Models Debate
}

\author{
Wim De Neys ${ }^{\mathrm{a}}$ \\ ${ }^{a}$ Université de Paris, LaPsyDE (UMR CNRS 8240), France
}

\begin{abstract}
In a previous article, I questioned whether the debate between dual- and single-process models of thinking is empirically tractable and argued that psychological scientists should leave it behind. Dewey (in press) suggests that by reframing the debate in cognitive modeling terms it might become tractable and consequential. More specifically, he proposes that focusing on the question as to whether analytic engagement (i.e., the process by which additional resources are allocated to a reasoning problem) is discrete or continuous might allow us to settle the debate. Here I illustrate how this suggestion will likely face the same tractability problems as the original defining features approach that it is supposed to replace.
\end{abstract}

\section{Introduction}

Proponents of single-and dual-process models of thinking have debated for decades whether there is a qualitative or only quantitative difference between intuition and deliberation. In a previous article (De Neys, 2021), I reviewed classic arguments and claimed that the current evidence does not allow us to decide the debate. Next, I questioned whether it was possible to settle the debate based on empirical evidence, and argued that even if it was, it would be irrelevant for psychologists because it does not advance the understanding of the processing mechanisms underlying thinking. My main conclusion was that it is time for empirical scientists to leave the debate behind and focus on more critical questions concerning the nature of intuitive and deliberate thinking.

In an interesting commentary, Dewey (in press) suggests that framing the debate in cognitive modeling terms might make it tractable and consequential. What is laudable is that Dewey moves beyond a simple generic claim by developing a concrete theoretical account (see also Dewey, 2021). Dewey's proposal focuses on analytic engagement: the process of engaging additional cognitive resources to the reasoning task at hand (e.g., De Neys, 2017; Pennycook et al., 2015; Thompson et al., 2011). Put differently, the process that allows us to switch from mere intuitive to more deliberate thinking. Dewey argues that determining whether analytic engagement is discrete or continuous allows us to settle the debate. He posits that a qualitative dual-process model needs to entail that analytic engagement is discrete: The engagement signal has only two states - "on" or "off" - and once it's switched on, it leads to a discrete amount of deliberation. A single-process model would entail that analytic engagement is continuous. A gradual increase in the analytic engagement signal leads to a gradual increase in deliberation (see Dewey, 2021, for a detailed account).

I believe Dewey points to a critical question and from a purely theoretical point of view, his suggestion is not unreasonable. The problem is that as soon as we would want to dig into any actual empirical testing, we'll presumably run into the same old issues that plague the classic defining features approach. I'll illustrate this with three simple examples. 
First, the proposal puts a lot of explanatory burden on the analytic engagement process. If we want to make any a priori predictions here we need to know how it needs to be conceptualized (i.e., what counts as analytic engagement?) and how we can empirically measure whether it's discrete or continuous in nature. In the ongoing work on conflict detection during thinking that Dewey refers to, the engagement signal is typically operationalized as intuitive doubt in one's response as reflected in a processing slow-down or confidence decrease relative to a baseline, for example (e.g., Bago \& De Neys, 2020; De Neys, 2012; Pennycook et al., 2015). This readily raises the threshold question. Would a nanosecond slow-down or a $0.01 \%$ confidence decrease count as an engagement signal? If not, how do we agree on and determine where the threshold lies? Without such a threshold it will be hard to decide the debate. To illustrate, imagine that after we observe some initial analytic engagement and discrete deliberation, the engagement signal shows a further nanosecond increase (i.e., slow-down). We next observe that this does not lead to any measurable additional deliberation. At this point, Dewey's dual-process theorist can argue that the discrete view is supported. A further engagement signal increase does not lead to further deliberation. However, the single process proponent would simply argue that the signal increase has not reached its minimal threshold yet. So to arrive at a tractable and consequential prediction we need the single- and dual-process theorist to agree on a threshold again. The defining features debate has shown just how problematic this can be.

Second, in addition to the engagement threshold, we also need to decide on what counts as "more" or "non-discrete" deliberation. Empirical testing of the claim will require that we set a defining feature (e.g., computational capacity, speed, ... ) so that we know what to measure and decide on a threshold again. Imagine that dual- and single-process theorists agree on the analytic engagement signal threshold. They observe that this threshold is hit and that the signal further increases with one unit (whatever they decided this unit to be). Next, they observe that following the one unit increase, a person reasons for an additional nanosecond longer or allocates $0.01 \%$ more computational resources to the reasoning process. Would Dewey's dual-process theorist ever agree that this qualifies as additional non-discrete deliberation? If not, where does the threshold lie or - more generally how close does the mapping between variation in the engagement signal and subsequent variation in deliberation need to be, to be qualified as discrete or continuous?

Third, this problem is further exacerbated by the fact that we'll need to distinguish between initial and subsequent deliberation. It is reasonable to assume that after initial deliberation, a reasoner can decide there is a need for additional deliberation (e.g., a problem is not resolved after some initial deliberation and one decides to work harder on it). Therefore, Dewey specifies that his proposal only concerns the initial deliberation engagement. Hence, even in Dewey's dual-process model, there might be further (discrete or continuous) resources allocated to additional deliberation after the initial discrete deliberation stage. But how are we to differentiate between initial and subsequent deliberation? Imagine that the single model proponent observes that after what they consider to be initial engagement, there is a further increase in deliberation beyond the initial deliberation amount. They argue this supports the continuous view. However, the dual-process proponent could simply argue that this results from subsequent deliberation following the initial discrete deliberation. To make predictions here we need to define a threshold or set a criterion. For example, initial deliberation amounts to $x$ time/resources allocated to the problem; anything above $x$ equals subsequent deliberation. How are we ever going to decide on this criterion? Here too the old threshold problem is back in full swing.

In sum, as soon as we'd want to start running empirical studies to decide the re-framed debate we risk being back at square one and we'll still need single- and dual-process proponents to agree on a threshold at which an increase in a continuous measure would be taken as evidence of a true qualitative/quantitative difference. At this point, all we'll have done is to move from a debate as to what counts as a defining feature to a debate as to what counts as discrete or continuous engagement. 
Dewey realizes the potential problem. He acknowledges that the actual empirical testing might be difficult or impossible. Nevertheless, he remains optimistic about the possibility of resolving the debate. I'm afraid that given the experience with the defining features approach, I'm far more pessimistic here ${ }^{1}$.

That being said, I do want to stress that Dewey points to an interesting question. Discussions of analytic engagement in the dual (or single) process literature have typically focused on whether deliberation is engaged (De Neys \& Pennycook, 2019; Pennycook et al., 2015) and less on the question as to how the amount of deliberation is decided on (although see Ackerman and Thompson, 20172). An organism that wants to avoid wasting scarce resources needs some means of adjusting the amount of limited resources it allocates to a problem. Hence, the more general question as to how well-calibrated the engagement process is (and what cues are being used to inform the decision, for example), is an interesting one. If we decide on some practical boundaries and operational definitions, we should manage to get at least a rudimentary indication of how fine-grained or sensitive the mapping is (e.g., more fine- or coarse-grained - or, if you wish, more discrete or more continuous like). Although I have no hopes that such experiments will ever satisfy the hardcore single- and dual-process theorists, they should contribute to a better specification of the analytic engagement process.

This underscores my general point that to advance our knowledge of human thinking it is more useful to focus on specific empirical questions rather than on theoretical arguments as to how we need to frame (or re-frame) quantitative and qualitative processing differences. My advice for single- and dual-process theorists therefore stands: drop the quantitative vs qualitative debate and focus directly on the outstanding empirical work.

\section{Acknowledgments}

I thank the Agence Nationale de la Recherche for their support (ANR-16-CE28-0010-01). I also thank Bence Bago and Caleb Dewey for a stimulating discussion.

\section{References}

Ackerman, R., \& Thompson, V. A. (2017). Meta-reasoning: Monitoring and control of thinking and reasoning. Trends in Cognitive Sciences, 21, 607-617.

Bago, B., \& De Neys, W. (2020). Advancing the specification of dual process models of higher cognition: a critical test of the hybrid model view. Thinking \& Reasoning, 26, 1-30.

De Neys, W. (2012). Bias and conflict a case for logical intuitions. Perspectives on Psychological Science, 7, 28-38.

De Neys, W. (Ed.) (2017). Dual Process Theory 2.0. Oxon, UK: Routledge.

De Neys, W. (2021) . On dual- and single-process models of thinking. Perspectives on Psychological Science. Advance online publication. doi.org/10.1177/1745691620964172

De Neys, W., \& Pennycook, G. (2019). Logic, fast and slow: Advances in dual-process theorizing. Current Directions in Psychological Science, 28, 503-509.

Dewey, C. (in press). Commentary on De Neys (in press) : Reframing single- and dual-processs theories as cognitive models. Perspectives on Psychological Science.

Dewey, C. (2021). Analytic engagement in single- and dual-process theories. Manuscript submitted for publication. https://calebdewey.com/wp-content/uploads/2021/04/Analytic-Engagement-in-Single-and-DualProcess-Theories.pdf

Kool, W., \& Botvinick, M. (2018). Mental labour. Nature human behaviour, 2, 899-908.

1 To be clear, I do not argue that Dewey's approach is by definition impossible or necessarily bound to fail. My point is that I'm pessimistic about the prospects and do not see how it would be consequential.

${ }^{2}$ See also the wider literature on mental effort allocation (e.g., Kool \& Botvinick, 2018; Shenhav et al., in press) 
Pennycook, G., Fugelsang, J. A., \& Koehler, D. J. (2015). What makes us think? A three-stage dual-process model of analytic engagement. Cognitive Psychology, 80, 34-72.

Shenhav, A., Prater Fahey, M., \& Grahek, I. (in press). Decomposing the motivation to exert mental effort. Current Directions in Psychological Science.

Thompson, V. A., Turner, J. A. P., \& Pennycook, G. (2011). Intuition, reason, and metacognition. Cognitive Psychology, 63, 107-140. 